\title{
Occupational Health Problems of Welders in Benin City, Nigeria
}

\author{
Isah E.C. and Okojie O.H.
}

\begin{abstract}
Welding exposes welders to a variety of work-related hazards, which may be deleterious to their health. The awareness of these hazards and the attitude towards them are important factors in the prevention of these hazards among the welders. This study assessed the level of awareness of the hazards, the work-related health complaints and the safety measures employed by the welders in a Nigerian setting. The study was carried out in Benin City, the capital of one the 36 States of Nigeria and was of a cross sectional design. A total sample of the welders was identified from a list of registered workshops and they were interviewed using semi-structured interviewer-administered questionnaires. Data obtained was analysed by the Computer Programme for Epidemiologic Research (CPER) and presented as frequency tables and graph. The average number of welders per workshop was 3.7 with all of them as males and with a mean age of $32.2 \pm 10.6 y e a r s$. The illiteracy rate was $3.3 \%$ and the school dropout rate was $14.9 \%$. The average level of use of protective devices was generally low (35.9\%) when compared to the levels of awareness of the workplace hazards (91.6\%) and the work-related health complaints (96.4\%). The most prevalent health complaints were arc eye injuries (75.7\%) followed by foreign bodies in the eyes (70.0\%), back/waist pain (52.1\%), metal fume fever (43.8\%) and cuts/injuries from sharp metals (37.7\%); while the common personal protective equipment used were coverall (31.2\%), eye goggles (35.9\%) and hand gloves (20.8\%). None of them used any form of ear or respiratory protection. The levels of awareness of occupational hazards and the work-related health problems among the welders though high was not commensurate with the use of safety and protective devices against the hazards. There is therefore need for health and safety education of these workers in order to promote positive health among them.
\end{abstract}

\section{INTRODUCTION}

The International Standard Classification of Occupations (ISCO) defined welders as workers who join and cut metal parts using flame or electric arc and other sources of heat ${ }^{1 .}$

KEY WoRDS: Occupational Health Hazards, Welders, Nigeria

Isah E.C. and Okojie O.H. Department of Community Health, University of Benin,

Benin City, Nigeria.

Correspondence: Isah E.C., Department of Community Health, University of Benin, Benin City, Nigeria. E-mail essyisah@yahoo.co.uk

(- CMS UNIBEN JMBR 2006; $5(1): 64-69$
There are varieties of these processes but the commonest types in Benin city, Nigeria are the gas welding by the use of oxyacetylene flame and the electric arc welding involving the use of electricity.

Welders are often exposed to potential workplace hazards that can be injurious to their health especially when exposure is on a regular and cumulative basis. The excessive high temperature generated by the hot oxyacetylene flame or the electric current may lead to burns and electric shocks ${ }^{2}$. Injuries such as lacerations and cuts by sharp or pointed metal panes, from high velocity particles and occasional explosions of the 
oxyacetylene gas tanks may also occur ${ }^{2}$. The excessive lighting (glare) and exposure to ultra violet radiation may lead to 'arc eye' or 'flash burn' injuries to the cornea, photokeratosis and double vision and consequent retinal damage ${ }^{2,3}$. Hearing impairment may result from exposure to high noise level produced by the welding machine. Welders are also exposed to noxious metal fumes containing a cocktail of metals like zinc, copper, cobalt, nickel, chromium, platinum, and their oxides leading to various respiratory dysfunctions and to the influenza-like condition known as metal fume fever ${ }^{4-7}$. There have been reports of carcinogenic and mutagenic effects due to chronic exposure to welding fumes in animals that may be extrapolated to man.$^{8-10}$. Other organs, which may be affected by welding fumes, include the kidneys ${ }^{11,12}$ and the reproductive organs leading to reduction in sperm count and fecundity ${ }^{13,14}$.

Welding offers employment to various individuals in Benin City, Nigeria. The welders are usually located around mechanic workshops, motor spare-parts markets and along major highways where they establish privately owned small-scale workshops with about 3-5 welders per workshop. They have no form of organised occupational health service.

Employment of safety measures and practices among welders are important ways of preventing or reducing the levels of health hazards associated with the occupation. It is therefore pertinent to assess the level of awareness of these hazards among welders and the safety measures and practices they adopt to safeguard their health, with a view to making recommendations on ways of ameliorating the effect of the hazards.

\section{MATERIALS AND METHODS}

The study, which was carried out in Benin City, an ancient town and the capital of Edo State in Nigeria, was of a cross sectional design. The total population of welders in the three local government areas (LGAs) in the city was included in the study. They were identified from a list of registered workshops obtained from their association headquarters in each of the LGAs andthey were interviewed using semi-structured questionnaires which were administered by the researchers. The questionnaires were pre-tested among twenty welders in a separate local government area of Edo State for validation. They contained questions on bio-data, knowledge of workplace hazards, attitude towards these hazards and preventive measures employed against the hazards. Each question was fully explained to the respondents to ensure adequate understanding of the issues being sought after. Data collected were thereafter analysed using the Computer Programme for Epidemiologic Research (CPER) ${ }^{15}$ and presented as frequency tables and graph with the level of statistical significance set at $p \leq 0.05$.

\section{RESULTS}

A total of 249 workshops were surveyed and 758 out of 921 welders interviewed, giving an average number of welders per workshop as 3.7 and a response rate of $82.3 \%$. Five hundred and fifteen (67.9\%) of the welders worked with oxyacetylene flame (gas welding) while 243 (32.1\%) were electric welders.

They were all males with a mean age of $32.2 \pm 10.6$ years with most of them, 460 (60.7\%) in the 20-39 years age bracket. Twenty-five (3.3\%) of the welders had no formal education, 336 (44.3\%) completed their secondary education while 113 (14.9\%) were school drop- outs (Table 1).

Table 2 shows that 694 (91.6\%) of the welders were aware of one or more workplace hazard while a total of 731 (96.4\%) had experienced one or more work-related health problem. The most common complaints were arc eye injuries $(75.7 \%)$; foreign bodies in the eyes $(70.0 \%)$; back/waist pain (52.1\%); metal fume fever (43.8\%) and cut/injuries to the hands and fingers (37.7\%). Comparisons 


\section{A. Age Distribution of Welders}

Age Interval (Years)

$<20$

20-29

30-39

$40-49$

50-59

$\leq 60$

Total
Frequency

$\begin{array}{rr}62 & 8.2 \\ 302 & 40.3 \\ 232 & 30.6 \\ 99 & 13.1 \\ 56 & 7.4 \\ 3 & 0.4 \\ 758 & 100.0\end{array}$

Mean age $=32.2 \pm 10.6$

95\% Confidence Interval $=31.5-33.0$

B) Ecucational Status of the Welders

\section{Educational Status}

Nil

Primary School Drop-out Completed Primary School Secondary School Drop-out

Completed Secondary School

Tertiary School

Total
Frequency

25
24
279
89
336
758

758
Percentage

3.3

3.2

36.8

11.7

44.3

0.7

100.0

Table 2: Level of Awareness of Occupational Hazards and Complaints among the Welders

\begin{tabular}{|c|c|c|c|c|}
\hline $\begin{array}{l}\text { Occupational } \\
\text { Health hazard }\end{array}$ & $\begin{array}{l}\text { Awareness } \\
\text { Frequency }(\%)\end{array}$ & $\begin{array}{l}\text { Complaints } \\
\text { Frequency (\%) }\end{array}$ & $\mathrm{x}^{2}$ Value & Pvalue \\
\hline 'Arc eye' injury & $683(90.1)$ & $574(75.7)$ & 55.3 & 0.000 \\
\hline Foreign body in eye & $689(90.9)$ & $566(74.8)$ & 70.0 & 0.000 \\
\hline Breathlessness & $21(2.8)$ & $41(5.4)$ & 6.7 & 0.009 \\
\hline Chronic cough & $572(75.5)$ & $138(18.2)$ & 498.9 & 0.000 \\
\hline Metal fume fever & $214(28.2)$ & $332(43.8)$ & 39.9 & 0.000 \\
\hline Cuts/injuries from sharp metals & $694(91.6)$ & $286(37.7)$ & 480.4 & 0.000 \\
\hline Burns & $210(27.7)$ & $116(15.3)$ & 34.5 & 0.000 \\
\hline Electric shock & $198(26.1)$ & $73(9.6)$ & 70.2 & 0.000 \\
\hline Explosion & $128(16.9)$ & $23(3.0)$ & 81.1 & 0.000 \\
\hline Back/waist pain & $665(87.7)$ & $395(52.1)$ & 228.6 & 0.000 \\
\hline Impaired hearing & $67(8.8)$ & $29(3.8)$ & 16.1 & 0.000 \\
\hline $\mathrm{Ni}$ & $64(8.4)$ & $27(3.6)$ & 16.0 & 0.000 \\
\hline
\end{tabular}

Figures not mutually exclusive; $n=758$

between the levels of awareness of occupational hazards with the occurrence of health complaints were all statistically significant, (p<0.05).

Figure 1 shows the types of protective/ safety equipments used by the welders. Only a total of 272 (35.9\%) used one or more types of protective device against work place hazards with eye goggles (35.9\%), coveralls
(31.2\%) and hand gloves (20.8\%) being more frequently used.

Table 3 shows associations between the different parameters assessed. There was a significant difference between the development of arc eye and eye protection $\left(X^{2}=4.5\right.$; $\mathrm{df}=1 ; \mathrm{p}=0.034$ ) as a high proportion (73.3\%) of those who did not use eye protection developed arc eye injury. However, there seem

( CMS UNIBEN JMBR 2006; 5 (1): 64-69 
Table 3: Associations Between Various Parameters Among The Welders

\begin{tabular}{|c|c|c|c|}
\hline \multirow[b]{2}{*}{ Use of Eye Protection } & \multicolumn{2}{|c|}{ Arc Eye Injury } & \multirow[b]{2}{*}{ Total } \\
\hline & Yes (\%) & No $(\%)$ & \\
\hline Yes & $218(80.1)$ & $54(19.9)$ & $272(35.9)$ \\
\hline No & $356(73.3)$ & $130(26.7)$ & $486(64.1)$ \\
\hline Total & $574(75.7)$ & $184(24.3)$ & $758(100.0)$ \\
\hline \multicolumn{4}{|l|}{$\mathrm{X}^{2}=4.5 ; \mathrm{df}=1 ; \mathrm{p}=0.034$} \\
\hline & \multicolumn{2}{|c|}{ Health Camplaints } & \\
\hline Duration on the Job (Years) & Yes (\%) & No $(\%)$ & Total \\
\hline $1-5$ & $66(84.6)$ & $12(15.4)$ & $78(10.3)$ \\
\hline $6-10$ & $110(97.3)$ & $3(2.7)$ & $113(14.9)$ \\
\hline $11-15$ & 158 (96.9) & $5(3.1)$ & $163(21.5)$ \\
\hline $16-20$ & $213(98.2)$ & $4(1.8)$ & $217(28.6)$ \\
\hline$\leq 21$ & $184(98.4)$ & $3(1.6)$ & $187(24.7)$ \\
\hline Total 731 (96.4) & $27(3.6)$ & $758(100.0)$ & \\
\hline \multicolumn{4}{|c|}{$\begin{array}{l}\text { Mean Durationfiltered }=15.6 \pm 6.4 \\
\mathrm{X}^{2}=23.1 ; \mathrm{df}=4 ; \mathrm{p}=0.000\end{array}$} \\
\hline
\end{tabular}

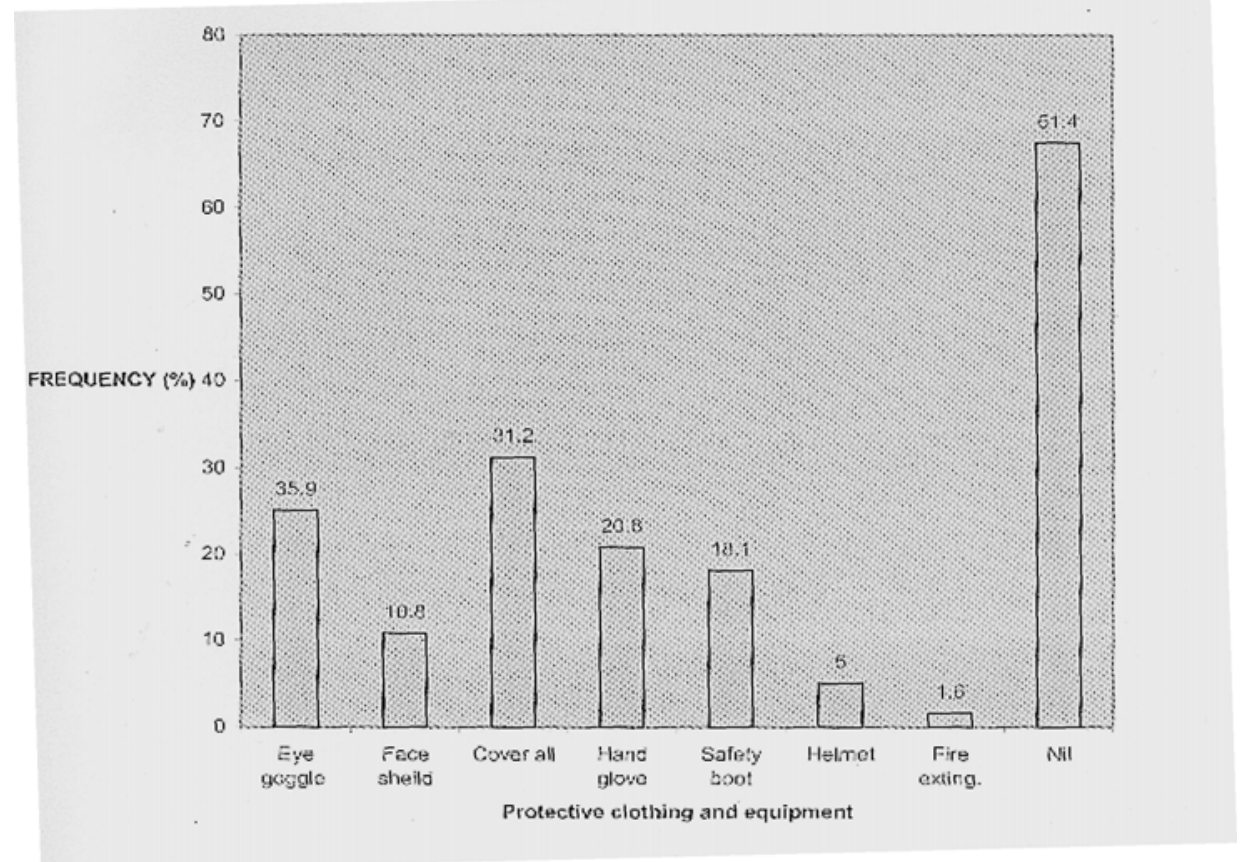

Figure 1: Type of Protective Devices Used

to be a paradox, as 80\% of those who used eye protection still developed arc eye injury. The association between the duration of work as a welder and the development of workrelated health complaints was also statistically significant. ( $\left.X^{2}=43.5 ; d f=4 ; p=0.000\right)$, the longer the duration of work, the more the work-related complaints by the welders.

\section{DISCUSSION}

Welding is a common small-scale industry in Nigeria and as with other occupations, is associated with its work place hazards that can affect the health of those engaged in it.

The welders in this study were all males, explaining the gender bias towards this occupation especially in a developing country 
like Nigeria. The finding that a majority (79.1\%) was in the 15 - 39 years age bracket was probably due to the apprenticeship setting where there are an average of 3 younger apprentices working under their masters. The figure of $14.9 \%$ of school dropouts, though lower than the $22.0 \%$ obtained in another study, ${ }^{16}$ shows a high rate of educational failures among this group.

The major risk from ultra violet radiation among welders is the "arc eye" or "flash" injury. This causes inflammation of the cornea and conjunctiva with consequent redness, intense pain and a feeling of "sand in the eyes". In this study 574 (75.7\%) of the welders had experienced arc eye injuries and this is in keeping with the figure of $73 \%$ obtained in another study ${ }^{3}$. As expected, a high proportion (73.3\%) of those who developed arc eye injury did not use eye protection. It is of interest to note that a significant proportion (80.1\%) of welders who used eye-goggles as a form of protection still developed arc eye injury. This may be due, in part to the improper use of these devices and a false sense of security on the part of the welders using them. Moreover, these devices may have been of sub standard quality and so lacked protective properties. The high incidence (70.0\%) of foreign particles in the eye and the significant proportion of injuries to the umprotected eyes, underscores the need for proper eye protection among this group of workers. The problems of visibility and comfortability of ocular protective devices have been addressed over the years with improvements made in their design to reduce the incidence of ocular injuries among welders ${ }^{17,18}$ Auto-darkening filters now being incorporated into the protective devices automatically change from a clear to a darkened state when the welding arc is struck thus allowing uninterrupted work by the welder ${ }^{17,18}$

Respiratory problems together with metal fume fever, which presents with flu-like symptoms accounted for a significant total of 511 (67.4\%) of health complaints among the

\footnotetext{
- CMS UNIBEN JMBR 2006; 5 (1) : 64-69
}

study group. The effect of noxious welding fumes on the respiratory system have been variously described. ${ }^{4-7}$ It is important to note that none of the welders used any form of nose masks or ear protection; this is probably due to their low perception of the occupational risks to the auditory and respiratory systems. As expected, the proportions of the welders with various health complaints increased over time though there was a minimal decrease among those who had worked for over 21 years.

A majority of the welders were aware that their jobs were hazardous to their health yet only a third used some form of protective measures against these hazards. The poor economic condition in the country has played a major role in the availability and affordability of these all-important protective devices.

There is need for proper education of this economically viable group on workplace hazards, the types and proper use of the different protective devices in order to safeguard their health. There is also need for a strong welder's union that should make adequate and proper representation to the appropriate tier of government. The Ministry of Labour and Productivity in conjunction with the Ministry of Health should collaborate to provide health care for this group of workers, as close as possible to where they live and work, in keeping with one of the principles of the primary health care programme.

\section{References}

1 International Labour Organisation (ILO) . International Classification of Occupations 1968. Revised Edition. International Labour Office. Geneva.

2. Shaikh TQ and Bhojani FA. Occupational injuries and perceptions of hazards among road-side welding workers. J. Pak. Med. Assoc. 1991; 41 (8) : 187-8.

3. Norn $M$ and Franck $C$. Long term changes in the outer part of the eye in welders. Prevalence of spheroid degeneration, pinguecula, 
pteryguim and cornea cicatrices. Acta ophtalmol Copenh. 1991; 69(3) : 382-6.

4. Coggen $D$, Inskip $H$, Winter $P$ and Pannett B. Lobar pneumonia: an occupational disease in welders. Lancet. 1994; 334: 41-3.

5. Ruegger IE. Respiratory symptoms impairment in shipyard welders and crawlker bumers. Brit. J. Ind. Med. 1995; 46: 292-301.

6. Contreras GR and Chan-Young M. Bronchial reaction to exposure to welding fumes. Occup-Environ. Med. 1997; 54 (11) : 836-9.

7. Bradshaw LM, Fishwick D, Slater $T$ and Pearce N. Chronic bronchitis, work-related respiratory symptoms and pulmonary functions in welders in New Zealand. Occup-Environ. Med. 1998; 55 (3) : 150-4.

8. Pasamen EJ, Berlin M and Rudell B. Bronchocarcinogenic properties of welding and thermal spraying fumes in the rat. Am. J. Incus. Med. 1986; 11: 39-54.

9. Li K and Yun P. A case control study of lung cancer in Florence. J. Epid. Comm. Hlth. 1988; 39: 244-50.

10. Haffman OT, Biggart NW and Rinchart RR. Evidence for the presence of mutagenic compound other than chromium in particles from mild steel welding. J. Resp. Med. 1998; 180: 55-65.
11. Vyskocil AJ, Hagberg M and Lindquist B. Exposure to welding fumes and chronic renal diseases. Int. Arch. Occup. Env. Hlth. 1992; 58: 191-5.

12. Nuyts GD, Van Vlem E, Thys J, De hurstijdex OD, Haese PC, Elseviers MM and De Broe ME. New occupational risk factor for chronic renal failure. Lancet. 1995; 346: 7-11.

13. Mortensen PJ. Fertility among Danish male welders. Scand. J. Env. HIth. 1988; 16: 315-22.

14. Bonde JP. Semen quality and sex hormones among mild and stainless steel welders: a cross sectional study. Brit. J. Ind. Med. 1990; 47: 508-14.

15. Abramson JH and Gahlinger PM. Computer Programmes for Epidemiologists; PEPI Version 3. Brixton Books, Llanidloes, Powys, Wales. 1999.

16. Isah EC, Okojie $\mathrm{OH}$ and Isah AO. Street trading: an aspect of child labour in Benin City, Nigeria. J Comm Med and Primary Health Care. 2001; 13: 48-52.

17. Proctor T. Protection of the eyes during welding. Occupational Health.1998; 41 (10) : 279.

18. Imberger A, Altmann A and Watson W. Unintentional adult eye injuries in Victoria Monash University. Hazard. 1999; 41: 4-5. 